ESTUDOS LITERÁRIOS 


\section{CACAU: ROMANCE DE PROPAGANDA}

Luís Gonçales Bueno de Camargo ${ }^{*}$

accat é um romance que não deixa lugar para o segredo. Tudo nele se propõe explícito ou, mais que isso, exemplar. Tudo concorre, numa espécie de tirania da consciência criadora, para um fim bem específico: o da propaganda política.

Eduardo de Assis Duarte, autor da mais recente abordagem ampla da obra de Jorge Amado, detecta como centro da construção de Cacal uma tensão entre propaganda e documento. De fato, esses dois elementos participam da construção do romance. Mas haverá entre eles tensão propriamente dita? Na própria formulação de Duarte encontramos uma resposta para isso:

As duas tendências convivem no texto na busca de uma síntese que as compatibilize. Só que em vários momentos o proselitismo sobrepõe-se ao documento, os sonhos comunistas se mostram mais fortes. Ao final, prevalece a esperança e o herói parte em busca da utopia.

* Universidade Federal do Paraná

1 DUARTE, Eduardo de Assis. Jorge Amado: romance em tempo de utopia. Rio de Janeiro: Record/Natal: EDUFRN, 1996. p. 61. Este livro faz uma discussão de conjunto da primeira fase da obra de Jorge Amado, de O país do carnaval (1931) a Subterrâneos da liberdade (1954). 
$\mathrm{Na}$ verdade, é difícil localizar no romance esse desejo de síntese entre documento e propaganda. Essa prevalência do doutrinário, que o crítico só vê ao cabo do livro, parece ser o verdadeiro fator construtivo do texto. A propaganda é o fim mais evidente do romance e o documento é o meio privilegiado para obtê-lo. Nessa perspectiva, a crítica social (que Duarte liga ao pendor realista, documental) não se esgota, antes reforça a propaganda, dá-lhe força. Por isso não me parece válida a idéia de que Cacau fracassaria ao buscar uma síntese entre duas forças que, em princípio, estariam em lugares opostos. A relação entre essas forças já aparece definida no plano básico do livro, e em seu desenvolvimento não há desequilíbrio simplesmente porque entre elas não há luta - seu lugar é o mesmo.

Assumir a propaganda como fim de Cacau me parece ser a única forma de tentar uma aproximação ao romance que escape da apriorística aceitação ou recusa do livro em si. Se olhamos a recepção que o livro tem tido, o que vemos é isso: ou elogios rasgados ou uma demolição radical.

No campo dos elogios, basta dar uma rápida olhada na crítica do período. Vários dos artigos publicados no Boletim de Ariel são francamente positivos. O mesmo acontece com a crítica do então todo-poderoso Agripino Grieco. ${ }^{2}$ Essa recepção, bem como o fantástico sucesso de público que o livro teve, acabaram lançando Jorge Amado, aos 21 anos, à posição de um dos mais importantes romancistas da década de 30 , ao lado de José Lins do Rego. ${ }^{3}$ Essa posição, aliás, seria consolidada em 1935 , com a publicação de Jubiabá, de maneira aparente: mente irreversível para a época.

No sentido contrário, temos uma célebre crônica de Manuel Bandeira e uma reação violenta de Octávio de Faria, que havia elogiado muito o primeiro romance de Jorge Amado, No pais do carnaval. ${ }^{4}$

Posteriormente a crítica universitária se empenhou bastante para cristalizar a visão de que o romance é ruim - lembrem-se Luiz Costa Lima, em sua 1948. p. $9-11$.

2 Ver GRIECO, Agripino. Gente nova do Brasil. 2. ed. Rio de Janeiro: J. Olympio,

3 O sucesso de público é em parte explicado pelo próprio Jorge Amado, no artigo "Em 1933 viajei do Rio para Maceio com o objetivo único de conhecer o romancista Graciliano Ramos", publicado na revista Exu, Salvador, Fundação Casa de Jorge Amado, n. 12, p. 18, nov./dez. 1989: "Eu vinha de publicar meu segundo romance, Cacau, meu primeiro sucesso de público: os dois mil exemplares da edição Ariel foram vendidos em quarenta dias - para isso concorreu grandemente o fato do livro ter tido sua circulação proibida pela polícia, o que resultou em farta publicidade."

4 Sobre a recepção do livro à época de seu lançamento, além dos artigos citados no corpo deste trabalho, ver TÁTI, Miécio. Jorge Amado: vida e obra. São Paulo: Martins, 1961. p. 47-56. 
colaboração para A literatura no Brasil, e Alfredo Bosi, que, na História concisa, desautoriza a obra toda de Jorge Amado, quase sem comentários.

Fábio Lucas sintetizou as causas dessa recusa não apenas a Cacau, mas à obra de Jorge Amado como um todo:

Os críticos apontam como defeitos persistentes na obra de Jorge Amado:

1. falta de complexidade interior nas personagens.

2. linguagem pouco trabalhada, ausência de experiência formais, construção romanesca e técnica nos moldes tradicionais.

3. ação por vezes emperrada pelo discurso (geralmente poético). ${ }^{5}$

É com essas restrições - ou contra elas, até certo ponto - que Assis Duarte dialoga. Contra esse verdadeiro consenso, sua atitude é a de tentar valorizar a obra, embora admitindo aqui e ali, quando parece inevitável, que as restrições têm razão de ser. Esse é o caso da superficialidade de construção das personagens:

A utilização de personagens sem maior riqueza interior era comum na época, sobretudo nas obras da vanguarda esquerdista. Fez-se presente com muito vigor no Expressionismo alemão e no teatro engajado de Brecht, Piscator e Meyerhold. No entanto, cumpriam ali uma função distinta, fruto de um projeto distinto: eram personagens estilizadas visando um efeito alegórico. $\mathrm{O}$ adensamento psicológico cedia lugar à representaçāo das relações vividas e suas determinaçōes históricas e econômicas. O mesmo não acontece no texto de Amado, movido por um interesse realista e que, portanto, necessitaria de figuras humanas mais complexas e verdadeiras para atingir a densidade simbólica própria ao gênero. Ao contrário, o personagem estereotipado em face única não consegue exibir aquela humana dose de contradição que o aproximá da vida real. Nesses aspectos, o livro vê enfatizado seu caráter de imaturidade, mostrando-se, de fato, como obra de aprendiz. ${ }^{6}$

5 LUCAS, Fábio. Plano, com epígrafe, de um estudo sobre a morte de Quincas Berro D'Água. In: AMADO, Jorge et al. Jorge Amado: povo e terra, 40 anos de literatura. São Paulo: Martins, 1972. p. 179-180.

6 DUARTE, op. cit., p. 61-62. 
O fato, em si, de admitir que as personagens de Cacau têm construção psicológica muito frágil é mesmo inevitável. O que me parece discutível aqui são as razões que o crítico aponta, baseadas na idéia de que o projeto do livro repousa no documental. Idéia, aliás, que contradiz a hipótese anteriormente feita, mencionada acima, de que Cacau "se constrói [...] na tensão entre o documento e a propaganda"?

Entender claramente que o que orienta o projeto de Cacau é sua intenção doutrinária pode dar um pouco mais de clareza a uma tentativa de, mais que julgar, compreender o romance.

Em primeiro lugar, compreender a recepção que este livro - e em certa medida toda a obra de Jorge Amado nos anos 30 - teve. As recusas e aceitações têm sido assim tão absolutas porque o que se aceita e recusa não é simplesmente um livro, mas todo um projeto literário, que Jorge Amado deixara explícito na famosa apresentação com que abriu Cacau. Basta contrastarmos algumas dessas posições antágônicas para aclararmos essa afirmação e observarmos que quase todas elas são precedidas por considerações sobre o que venha a ser o romance.

Dentre os que consideraram o livro excelente está Alberto Passos Guimarães, que faz seu julgamento de Cacal ser precedido por observações como esta:

Há uma arte nova. Mas essa arte não é simplesmente a renovação do processo de composição, nem dos gêneros nem das formas. Há uma arte nova como conseqüência da renovação do ambiente social e com íntimas diferenças de natureza que a distancia às léguas dos passados conceitos de arte. Há uma arte nova, ligada ao movimento de emancipação de uma classe, refletindo todos os aspectos da luta por esta emancipação. ${ }^{8}$

Entre aqueles que não gostam do livro, o que há é uma recusa entre uma eventual diferenciação entre romance proletário e romance simplesmente, sem adjetivos. Essa recusa foi longamente desenvolvida por Octávio de Faria e Marques Rebelo, mas foi Manuel Bandeira quem, numa só frase, seca e direta, a resumiu: "E proletário ou não, Cacau como romance é muito defeituoso."9

7 DUARTE, op. cit., p. 61 .

8 GUIMARÃES, Alberto Passos. A propósito de um romance: Cacau. Boletim de Ariel, Rio de Janeiro, ano 2, n. 11, p. 288, ago. 1933.

9 BANDEIRA, Manuel. Impressões literárias. In: Poesia e prosa. Rio de Janeiro: J. Aguilar, 1958. p. 1.195. 
Em segundo lugar - e mais importante - entender Cacau como uma proposta de romance doutrinário, nada mais que isso, pode ajudar a compreender a lógica interna do próprio romance. Ora, propaganda é discurso de convencimento, exemplo de função conativa da linguagem. Seu objetivo é atingir diretamente aquele que se expõe a ela. Nesse sentido, a lógica do romance pensado como propaganda passa muito mais pela retórica do que propriamente pela verossimilhança em seu sentido mais estrito, de possibilidades semelhantes às da realidade factual. Dizendo de outro jeito, um romance como Cacau, uma vez que construído sob a égide da propaganda, instaura uma rede específica de causalidades, estabelece uma outra verossimilhança, de validade puramente interna. Mal comparando, trata-se de uma espécie de "discurso engenhoso", no sentido que António José Saraiva o define ao tratar de Vieira, que engendra um padrão lógico que lhe é próprio.

Tudo em Cacau, à maneira de argumento, participa para conduzir o romance numa certa linha de raciocínio. Veja-se, por exemplo, o defeito que mais se apontou no livro à época de seu lançamento, o maniqueísmo: "[...] todos os proletários são bons, ou pelo menos desculpáveis, e o resto da humanidade que passa no romance, umas pestes." velhacos, libidinosos e... católicos." "; "[...] esse Cacau onde todos os 'de cima', os ricos, são maus e onde todos os 'de baixo', os pobres, são bons." "12

É evidente que na realidade factual as coisas não funcionam exatamente dessa forma, como assinalou Manuel Bandeira: "Ninguém melhor do que Jorge Amado sabe que a vida nã̀o é tão simples assim.""13

É bem provável que Jorge Amado soubesse disso, sim. Mas até que ponto isso importa no projeto deste romance? Trata-se de propaganda. Na luta de classes só há dois lados, o do capital e o do trabalho. Se se está de um lado, não se pode estar do outro. Nada mais natural, então, para tornar mais exemplares e claras as situações, que o contraste seja forte e que não haja qualquer forma de matização. Até mesmo o repisar de certas características é importante, dando ênfase ao claro-escuro. Veja-se, por exemplo, os retratos físicos dos dois capitalistas presentes no livro:

10 BANDEIRA, op. cit., p. 1.195.

11 TABAYÁ, Arnaldo. Um romance proletário. Boletim de Ariel, Rio de Janeiro, ano 3. n. 1, p. 20 , out. 1933 .

12 FARIA, Octávio de. Jorge Amado e Amando Fontes. Boletim de Ariel, Rio de Janeiro, ano 3, n. 1 , p. $7-8$, out. 1933 .

1.3 BANDEIRA, op. cit., p. 1.195. 
Meu tio, o dono, estava bem mais velho e mais vermelho e mais rico. A barriga era o îndice de sua prosperidade. À proporção que meu tio enriquecia ela se avolumava. Estava enorme, indecente, monstruosa. ${ }^{14}$

O coronel possuía uma voz arrastada, demorada, cansada, de animal sagaz e uns olhos maus, metidos no fundo. da cara enrugada pela idade. Cultivava, como meu tio, uma barriga redonda, símbolo da sua fartura e da sua riqueza. Sabia-se que comia muito, comia estupidamente [...]. (p. 142)

É evidente que há capitalistas magros também. Mas isso não interessa ao narrador de Cacau. É preciso, como propaganda, deixar na mente do leitor uma imagem única, bem fixa, desse capitalista. Se todos se parecerem fisicamente, é mais conveniente e mais fácil estabelecer essa imagem. Ou seja, é uma estratégia mais eficaz de propaganda.

Demonstração cabal de que esse maniqueísmo é intencional é o fato de que uma das personagens ricas, Mária, a filha do fazendeiro, aponta o problema quando conversa com o personagem-narrador Sergipano: "- Não seja tolo. Enraivecia-se. - Vocês também odeiam a gente sem saber se há bons e maus." (p. 150)

O Sergipano não responde a isso - nem contesta, nem confirma. Sua reação é contar sua própria história para Mária. Esse momento é signicativo: é como se a própria história e aquilo que ela representa justificassem esse tipo de despreocupação de matizar moralmente as personagens. Nesse trecho se encontra a justificativa para que a história, enquanto história exemplar, esclareça tudo e simplesmente dispense a ponderação. Um outro caso interessante a se pensar é o do misto de matador e "alugado" Honório. Uma breve aproximação desse personagem com o matador que aparece evocado por Luís da Silva em Angústia vai mostrar bem o que se quer dizer aqui. José Baía - ao contrário do próprio Luís da Silva, que manifesta o desejo de ser como ele - mata sem qualquer raiva, por puro profissionalismo, sem se importar com quem vai morrer, se rico, se pobre, homem, mulher, gordo ou magro. Ora, para o projeto de Cacau isso absolutamente não interessa. $O$ ato de vontade de Honório, poupando Colodino e complicando sua própria posição diante do fazendeiro, é necessário para

14 AMADO, Jorge. No país do carnaval. Cacau. Suor. São Paulo: Martins, [s.d.]. p. 108. Adiante aparecerá, entre parênteses, o número da página citada. 
mostrar a existência de algo.chamado "consciência de classe". Se, em princípio, não parece muito verossímil que um matador vá fazer o que Honório fez (deixar de matar alegando que não mata pobre), em Cacau, um romance que tem como elemento construtivo a propaganda, é necessário que ele o faça.

Um terceiro ponto a se examinar é a religião. Os padres são sempre patifes, que fazem conluio com os patrões, colaborando na exploração dos proletários e ensinando a seus filhos uma confusa religião na qual Deus se confunde com o patrão e onde apenas o conformismo é premiado. Como sempre, não há exceção, e os padres compartilham o destino que os ricos em geral têm no livro - o de serem os vilões. Mas esse não é o único aspecto da religiāo a ser notado no livro. Há um outro, apontado por Arnaldo Tabayá: "Os 'alugados' não têm religião (será isso possível no Brasil, onde se conhece o povoado pela torre da igreja?), no entanto os ricos são católicos, e o filho do patrão, tipo vulgar e velhaco, vai à missa com uma fita no pescoço." 15

Mais uma vez, a propaganda cria a necessidade de deixar de fora tudo aquilo que pode afastar da visão que ela quer. consagrar. Há, nesta atitude do narrador de Cacau, mais que a crítica à Igreja, um desejo de suprimi-la - e mesmo a instauração, no universo ficcional, dessa supressão. Não custa repetir: em princípio absurda, confrontada com a realidade brasileira, a ausência de rcligião é necessária como recurso retórico, como argumento no sentido de convencer o leitor de que as estruturas burguesas estão todas podres e precisam cair.

Esses três aspectos são apenas alguns dos exageros simplificatórios de Cacııı, mas são suficientes para comprovar que eles não são devidos a um descuido ou uma incapacidade do autor: são, isso sim, programáticos. $O$ aspecto documental interessa apenas para reforçar a propaganda e se concentra na descrição do trabalho árduo dos alugados. Se a figura de Honório, a maldade dos ricos $e$ a absoluta falta de religião da população mais pobre fogem do documental - ou do realismo -, é porque não interessam para a propaganda.

É claro que notar que esse procedimento é intencional não transforma Cacalı num grande romance. Mas é claro também que isso torna bem visivel o quanto é simplificador simplesmente aceitarmos indefinidamente as restrições automáticas que se vêm fazendo ao livro ou mesmo ao autor. Aponta também para o fato de que o estudo de obras eventualmente fracas do ponto de vista estético, mas significativas do ponto de vista da história literária, pode ser mais rendoso se se propuser a mergulhar no método utilizado pelo autor - ao invés

15 TABAYÁ, op. cit., p. 20. 
de se ficar cobrando delas o que não podem ser, isto é, obras paradigmáticas do gênero a que pertençam.

Nessa perspectiva, o caso a se discutir a respeito de Cacau é se esse projeto de romance-propaganda se concretiza, sem brechas, durante toda a obra. $\mathrm{O}$ que intercssa saber é se ele se mantém fiel à rede de causalidades que a propaganda instaura em seu interior, ou seja, se as eventuais "simplificações" vão sempre no mesmo caminho, construindo um todo uno.

A visão a respeito do casamento é bem esclarecedora nesse sentido. Num universo em que as instituições sociais tradicionais são desenhadas como decadentes e mesmo nocivas, é natural que apareça em Cacau um trecho como este: "A outra foi morar com Simeão sem bênçãos desnecessárias de juiz e padre." (p. 134)

Fica claro que a justiça e a religião, sendo dos ricos e dos padres, carecem de significado real e, portanto, são dispensáveis para dar legitimidade aos relacionamentos - especialmente entre proletários. Essa passagem não destoa do tom de propaganda do livro e mesmo colabora com ele.

Mas há um outro momento em que o casamento merece atenção do narrador: a festa de São João, propícia para mocinhas solteiras se entregarem àquclas formas tradicionais de anteverem seu futuro casamento. Tanto as moças ricas quanto as pobres participam de um mesmo ritual: ver, na água parada em uma bacia, seu futuro par. Esse ritual se concretizará de formas bem diversas. As pobres procurarão esse rosto em uma bacia qualquer. "Na casa-grande também olhavam na bacia de água. E que bacia bonita, de uma louça de nome complicado, com pinturas." (p. 154)

Aparentemente tudo mantém o projeto inicial: até o mais igualmente humano dos sentimentos se reveste de brilho ou de obscuridade de acordo com a escala social. Mas em torno desse ritual de moças, o narrador fará o seguinte comentário, acerca das moças pobres: "Noivos... Raras teriam noivos. Amásios, sim, e quantos..." (p. 154)

De repente, a ausência do casamento institucionalizado, que havia sido encarada com naturalidade, aparece como algo a se lamentar. Ao invés de pessoas que se relacionavam amorosa e sexualmente sem necessidade de qualquer legitimidade conferida pelas esferas ligadas ao poder, temos aqui pessoas designadas por um termo facilmente usado pelos burgueses falsos moralistas: amásios. Isso sem mencionar aquele quantos, que fecha o período.

No plano da moral sexual, embora num artigo famoso sobre Os corumbas Jorge Amado dissesse que o romance proletário seria desprovido de "senso de imoralidade", tal senso aparece claramente expresso aqui. ${ }^{16}$

I6 AMADO, Jorge. P.S. Boletim de Ariel, Rio de Janeiro, ano 2, n. 11, p. 292, ago. 1933. 
Vale frisar que, se fosse uma das moças solteiras a lamentar o fato de que jamais se casaria "normalmente", não haveria grande contradição no projeto doutrinário do romance. Haveria talvez um pequeno rompimento naquela divisão tão fortemente construída ao longo do romance entre pobres e ricos, mas se poderia creditar isso aos restos de moral convencional de que essas proletárias não conseguiriam fugir. No entanto, trata-se de expressão direta do pensamento do diligente narrador - é de sua voz que essa nota dissonante vai surgir. É portanto na voz autorizada para contar a história e conduzi-la dentro de uma visão de mundo "proletária" que se vê essa fratura.

A própria configuração desse personagem-narrador deixa entrever que o tecido rígido da propaganda se esgarça em alguns pontos. Em primeiro lugar, $\mathrm{cm}$ sua própria história pessoal. Bandeira reclama do desenho dessa personagem:

[O romance é] mal colocado no seu primeiro arcabouço, porque aquele rapaz pequeno-burguês que vira trabalhador de enxada $\mathrm{c}$ mais tarde vem escrever o romance é de todo inaceitável. Não viraria trabalhador de enxada, e se porventura o fizesse não escreveria na maneira requintada, apesar de todos os palavrões, em que se exprime Jorge Amado. ${ }^{17}$

Novamente, o problema a nos interessar aqui não é propriamente o da verossimilhança, como aponta Bandeira. Em certo sentido, o fato de ter uma origem dentro das classes dominadoras contribui para a tragédia pessoal da personagem, além de indicar que os favores do capital são muito instáveis e só se multiplicam para pessoas de fato más, capazes de pensar apenas em si próprias. Essa é, aliás, uma das linhas de desenvolvimento do romance. $\mathrm{O}$ coronel Misael tem consciência disso e teme o cacau, que para ele é a concretização do capital. Seu medo se revela quando castiga terrivelmente aqueles que estragam uma única fruta de cacau.

Do ponto de vista do desenho interno do romance, a pergunta a se fazer não é se o pequeno-burguês poderia ou não se transformar em trabalhador de enxada, mas sim por que isso teria de ser assim. Por que o herói é o Sergipano e não o Colodino? Por que um proletário de raízes proletárias não poderia seguir o caminho - de conscientização e de luta - que segue o Sergipano e, depois de aprender a ler e escrever, finalmente contar em livro essa sua pequena epopéia? 
Por que essa função - que, além de ser a de quem tem a palavra é também a do próprio intelectual - tem que ser de alguém com raízes burguesas? É como se o escritor estivesse justificando sua própria posição ao assumir-se como porta-voz de uma classe à qual não pertence, mas que, pela observação e por uma espécie de espírito de solidariedade, conhece e compreende. Ora, do ponto de vista da estratégia retórica regida pela intenção de propaganda, não haveria qualquer problema em caracterizar um narrador proletário em primeira pessoa. Ao contrário: a instauração de um narrador que adquire consciência e, ao mesmo tempo, adquire os meios intelectualizados de exercer essa consciência, participaria da mesma estratégia da construção da trajetória de Honório, que faz prevalecer a consciência de classe sobre o cumprimento de um "dever de matador".

A impressão que se tem aqui é a de que Jorge Amado abandonou as necessidades internas de seu romance-propaganda e se preocupou com a verossimilhança externa, ou seja, com o ser eventualmente pouco crível o fato de um operário semi-analfabeto escrever um livro. Sua intuição, nesse sentido, foi certeira, e o demonstra a recepção de São Bernardo, de Graciliano Ramos. Um dos pontos mais discutidos do livro foi justamente o fato de um matuto como Paulo Honório escrever tão bem como é o caso do narrador do romance. Na sua resenha do livro, Lúcia Miguel Pereira diria o seguinte: "Pois, parece incrível, mas neste seu último e notável romance o único defeito é ser bem escrito demais. Entendamo-nos: bem escrito demais para ser narrado por esse áspero Paulo Honório que aprendeu a ler na prisão."18

Em 1947, mais de dez anos depois do lançamento do livro, Álvaro Lins ainda se preocuparia com o fato: "O principal defeito de São Bernardo já tem sido apontado mais de uma vez: é a inverossimilhança de Paulo Honório como narrador, é o contraste entre o livro e o seu imaginário escritor, o que já se verificara em Caetés." 19

Tudo indica que, aqui, Jorge Amado tenha se deixado levar, também ele, por uma visão estereotipada do proletário, muito comumente visto no período como possuidor de uma alma simples e um entendimento também simples do mundo.

18 PEREIRA, Lúcia Miguel. Graciliano Ramos: São Bernardo. Gazeta de Notícias, Rio de Janeiro, p. 5, 23 dez. 1934.

19 LINS, Álvaro. Valores e misérias das vidas secas. In: Os mortos de sobrecasaca. Rio de Janeiro: Civilização Brasileira, 1963, p. 162. A esse respeito, ver a discussão que faz Eliane Zagury em seu ensaio "Graciliano Ramos e o modernismo clássico", publicado em $A$ palavra e os ecos (Petrópolis: Vozes, 1971). 
Esse mesmo problema se reflete numa certa indefinição do lugar em que se coloca e de onde fala o Sergipano. Para verificarmos isso basta contrapormos dois trechos em que ele aparece em relação a Colodino. "Apesar dos seus vinte e sete anos, Colodino, que sabia ler e escrever, tocava viola e falava certo, parecia-nos um mestre." (p. 151, grifo meu)

Nesse momento, Sergipano é um ser diferente de Colodino. Embora também saiba ler e escrever, e também fale certo, o Sergipano se identifica com os camponeses analfabetos. Ou seja: embora tenha as mesmas características de Colodino, ele se coloca mais próximo daqueles que não as têm.

Um pouco depois, o que se lê é o seguinte:

Os filhos dos coronéis são semideuses despóticos que amam deflorar por farra tolas roceiras de pés grandes e mão calosas. Pernósticos, falando difícil como quem sabe gramática, brutos e mal-educados, esses meninos me causavam um nojo medonho. Colodino também não os tolerava e não me lembro de haver ouvido o carpinteiro responder a qualquer pergunta dos acadêmicos. (p. 158)

Aqui, no contraste com os filhos da burguesia, há identificação entre Sergipano e Colodino. Ambos são iguais, operários alfabetizados que desprezam os salamaleques lingüísticos da língua artificial falada por aqueles.

É como se a cada momento o narrador-personagem sentisse a necessidade de afirmar seu estatuto de proletário. No contraste com o proletário mais "culto", ele se identifica com os outros - no fundo, "mais proletários" do que aquele. Em contraste com a burguesia, quando não há nada a provar, ele se sente à vontade para se igualar a Colodino. É uma espécie de má consciência vigilante a dele, que pressente que sua permanência do lado certo depende de um cuidado constante, de um esforço contínuo para se ver como proletário, muito ao contrário da pretensa naturalidade com que se recusa a se tornar patrão casandose com Mária.

Confirma essa atitude a maneira pela qual se constitui esse narrador em primeira pessoa. Apesar de seu esforço para dar uma visão da vida proletária como partícipe dela, nota-se uma hesitação. Basta ver a abertura do livro, que faz o leitor pensar que lerá um romance em terceira pessoa:

As nuvens encheram o céu até que começou a cair uma chuva grossa. Nem uma nesga de azul. $\mathrm{O}$ vento sacudia as árvores e os 
homens seminus tremiam. Pingos de água rolavam das folhas e escorriam pelos homens. Só os burros pareciam não sentir a chuva. Mastigavam o capim que crescia em frente ao armazém. Apesar do temporal os homens continuavam o trabalho. (p. 102)

A cena aparece vista por um olhar de fora. O objeto da atenção do narrador são os "homens" - a palavra é obsessivamente repetida, três vezes num curto trecho. Nada liga o narrador aos homens, nada pode fazer o leitor supô-lo um desses "homens". Para ser preciso, é necessário que se leiam quarenta parágrafos para que o narrador se revele como partícipe dessa cena coletiva de trabalho diário: "Nós ganhávamos três mil e quinhentos por dia e parecíamos satisfeitos." (p. 103)

Uma vez que não se encontra qualquer funcionalidade nesse "ocultamento" da primeira pessoa - que, diga-se, não é mais usado no romance -, tudo indica que se trata de mais um sintoma da dificuldade desse narrador em se ver como proletário. Embora explicitamente ele reafirme a todo instante que é igual a todos os alugados do coronel Misael, essa sua atitude vacilante o contradiz e nos revela mais um rompimento no projeto de romance-propaganda a que Cacau se propõe.

Tomando como ponto de referência o "grande romance", é claro que Cacaı é bastante simplificador. Podemos, dependendo de nossa simpatia pelo autor, chamá-lo de "romance fraco", como faz Luiz Costa Lima, ou de "romance de aprendiz", como quer Eduardo de Assis Duarte. De uma forma ou de outra, cssa postura acaba sugerindo que deixemos este romance de lado para tratar de obras que valham mais a pena.

O que se esboçou aqui foi uma outra abordagem. Jorge Amado tinha um projeto literário bastante sério na época em que escreveu Cacal, o de dar solidez ao romance proletário no Brasil - um projeto compartilhado por muitos outros intelectuais. Ora, não faz parte de um projeto dessa natureza a intencional confecção de maus romances, mas sim a confecção de um tipo de romance que nem sequer pretende participar do "grande romance", que seria classificado pcjorativamente de "romance burguês". Tentando identificar qual o projeto básico da obra - a propaganda que se vale do documento -, notamos que o livro neutraliza as acusações de simplificação ou, pelo menos, é possível notar certa funcionalidade nessa simplificação.

Isso não significa, entretanto, que se deva concluir que o livro, sendo assim, fica perfeito: é possível apontar incoerências mesmo dentro de seu projeto de desenvolvimento. Isso pode levar os maldosos a pensar apenas que todo este trabalho foi inútil, porque se acabou chegando à conclusão de que o romance, 
mesmo como propaganda, é ruim. Mas, para quem interessa entender a literatura brasileira dos anos 30 e a importância do jovem Jorge Amado nela, o trabalho é bastante útil: mostra concretamente um impasse que muitas vezes é apenas intuído. E como a arte socialmente interessada é uma constante na literatura brasileira, pode ajudar também a estabelecer uma forma de compreendê-la.

\title{
RESUMO
}

Este artigo pretende demonstrar que a propaganda política - e não o realismo documental - sustenta o projeto literário de Jorge Amado em Cacau, e ainda verificar a coerência desse projeto.

Palavras-chave: ficção brasileira, Jorge Amado, romance de 30.

\begin{abstract}
This article intends to show that political propaganda - and not documental realism - is the frame of Jorge Amado's literary project in the novel Cacau and also verify the coherence of that project.
\end{abstract}

Key words: Brazilian fiction, Jorge Amado, Brazilian novel of the thirties.

\section{REFERÊNCIAS BIBLIOGRÁFICAS}

AMADO, Jorge. No país do carnaval. Cacau. Suor. São Paulo: Martins, [s.d.]. . P.S. Boletim de Ariel, Rio de Janeiro, ano 2, n. 11, ago. 1933.

- Em 1933 viajei do Rio para Maceió com o objetivo único de conhecer o romancista Graciliano Ramos. Exu, Salvador, Fundação Casa de Jorge Amado, n. 12, nov./dez. 1989.

BANDEIRA, Manuel. Impressōes literárias. In: Poesia e prosa. Rio de Janeiro: J. Aguilar, 1958.

BOSI, Alfredo. História concisa da literatura brasileira. São Paulo: Cultrix, 1989. 
DUARTE, Eduardo de Assis. Jorge Amado: romance em tempo de utopia. Rio de Janeiro: Record/Natal: EDUFRN, 1996.

FARIA, Octávio de. Jorge Amado e Amando Fontes. Boletim de Ariel, Rio de Janeiro, ano 3, n. 1, out. 1933.

GRIECO, Agripino. Gente nova do Brasil. 2. ed. Rio de Janeiro: J. Olympio, 1948.

GUIMARÃES, Alberto Passos. A propósito de um romance: Cacau. Boletim de Ariel, Rio de Janeiro, ano 2, n. 11, ago. 1933.

LIMA, Luiz Costa. Regionalismo. In: COUTINHO, Afrânio (Org.). A literatura no Brasil. 3. ed. Rio de Janeiro: J. Olympio/UFF, 1986.

LINS, Álvaro. Valores e misérias das vidas secas. In: Os mortos de sobrecasaca. Rio de Janeiro: Civilização Brasileira, 1963.

LUCAS, Fábio. Plano, com epígrafe, de um estudo sobre a morte de Quincas Berro D'Água. In: AMADO, Jorge et al. Jorge Amado: povo e terra, 40 anos de literatura. São Paulo: Martins, 1972.

PEREIRA, Lúcia Miguel. Graciliano Ramos: São Bernardo. Gazeta de Notícias, Rio de Janeiro, 23 dez. 1934.

TABAYÁ, Arnaldo. Um romance proletário. Boletim de Ariel, Rio de Janeiro, ano 3, n. 1, p. 20, out. 1933.

TÁTI, Miécio. Jorge Amado: vida e obra. São Paulo: Martins, 1961.

ZAGURY, Eliane. Graciliano Ramos e o modernismo clássico. In: A palavrae os ecos. Petrópolis: Vozes, 1971. 